\title{
Impacts, mega-tsunami, and other extraordinary claims
}

Nicholas Pinter* and Scott E. Ishman, Dept. of Geology,

Southern Illinois University, Carbondale, Illinois 62901-4324, USA

Recognition of the importance of impact cratering ranks among the most significant advances in earth and planetary sciences of the twentieth century, but recently there has been a proliferation of reports of impact events and sites that eschew simple, less spectacular alternative explanations. Here we focus on (1) Holocene-age ocean impacts and associated "mega-tsunami," and (2) a catastrophic impact event suggested at $12.9 \mathrm{ka}$. Carl Sagan once said that "extraordinary claims require extraordinary evidence"; we argue that these impacts do not meet that standard.

In November 2006, the New York Times (Blakeslee, 2006) reported the identification of a growing number of impacts and associated mega-tsunamis during the past 10,000 yr by the "Holocene Impact Working Group." In contrast, using astronomical and planetary data, Bland and Artemieva (2006) calculated that impacts capable of "producing hazardous tsunami" occur only once every $\sim 100,000$ yr. Identification of Holocene megatsunamis was based largely on "chevrons," a new term for coastal landforms attributed to mega-tsunami run-up (e.g., Masse et al., 2006). Madagascar chevrons were linked to an Indian Ocean "crater" identified by ocean-floor topography and "splashes of iron, nickel and chrome fused" to foraminiferal tests in nearby ocean cores (Blakeslee, 2006; Abbott et al., 2007). The melting points of iron, nickel, and chrome are $>1400{ }^{\circ} \mathrm{C}$, whereas $\mathrm{CaCO}_{3}$ decomposes at $\sim 500{ }^{\circ} \mathrm{C}$. No studies of the K-T impact have reported foraminifera with fused metals. Identifying impact sites by searching for dimples on Earth's surface is a dubious proposition. For example, Speranza et al. (2004) documented a sheep watering hole identified as the "Sirente Crater."

To test the Holocene impact/mega-tsunami story, we collected meteorological data from two "chevron" sites: Montauk, New York, and Faux Cap, Madagascar (Gusiakov, 2006). In both cases, these features were precisely aligned with the dominant wind direction (Fig. DR1 [see the GSA Data Repository ${ }^{1}$ ) and had been mapped previously as parabolic dunes (LeBigre and Reaud-Thomas, 2001). We suggest that these Holocene features are clearly eolian, and that the term "chevron" should be purged from the impact-related literature.

Just as close scrutiny of the Holocene impacts belies an extraterrestrial source, an impact on the southeastern Laurentide ice sheet at $12.9 \mathrm{ka}$ proposed at the 2007 American Geophysical Union Joint Assembly (Firestone et al., 2007a, 2007b) engenders similar doubts. This purported impact is cited as a trigger for the Younger Dryas climate event, extinction of Pleistocene mega-fauna, demise of the Clovis culture, the dawn of agricul- ture, and other events (Firestone et al., 2007a, 2007b). Evidence of the 12.9-ka impact includes magnetic grains, microspherules, iridium, glass-like carbon, carbonaceous deposits draped over mammoth bones, fullerenes enriched in ${ }^{3} \mathrm{He}$ (Becker et al., 2007), and micron-scale "nanodiamonds" (Firestone et al., 2007c). We suggest that the data are not consistent with the $4-5-\mathrm{km}$-diameter impactor that has been proposed, but rather with the constant and certainly noncatastrophic rain of sand-sized micrometeorites into Earth's atmosphere.

The 12.9-ka impact story has struggled to bring its disparate evidence under a single umbrella. The impact story originated in Firestone and Topping (2001) and the Firestone et al. (2006) book, both of which contain observations and claims so wild that other work by these authors invites careful scrutiny. The nature of the 12.9-ka event changes radically with each iteration, from a supernova-generated "cosmic ray jet" (Firestone et al., 2006) to a massive atmospheric airburst (Firestone et al., 2007a, 2007b) to "multiple ET airbursts along with surface impacts" (Firestone et al., 2007c). Airbursts are a convenient explanation, given the lack of an impact crater, tektites, shocked quartz, or high-pressure minerals. Airburst events are associated with small impactors, perhaps <160 m diameter (e.g., Chapman and Morrison, 1994). Furthermore, the 12.9-ka event is identified as an oblique strike with "high-speed projectile material" (Firestone et al., 2007a) creating the elliptical "Carolina Bays" of the southeastern United States. Yet, of all impacts in the solar system, only a handful represent strikes capable of generating visibly elliptical forms (Pierazzo and Melosh, 2000). No meteorite material has ever previously been recovered from the Carolina Bays. Firestone and colleagues return to an impact origin for the Bays, ignoring a half-century of mainstream research focused on geomorphic mechanisms and age control documenting formation over extended time (Grant et al., 1998; Ivester et al., 2007). Similar elliptical depressions in Argentina, once claimed as an oblique impact swarm, were recently debunked and are now recognized as eolian (Bland et al., 2002).

The 12.9-ka impact story also has struggled with the broad range of impact-related materials reported. Firestone and Topping (2001) identified chondrules, suggesting that the impactor was a chondrite. Magnetic grains and spherules (Firestone et al., 2007a, 2007b, 2007c) are consistent with an iron-rich meteoroid, whereas silicate material (Firestone et al., 2007c) suggests a stony meteoroid, and "glass-like carbon" and carbon spherules suggest a carbonaceous source. Firestone et al. (2006, 2007a) suggest geochemical affinities with lunar crustal material. Any one of these might be a credible extraterrestrial source, but together they are a Frankenstein monster, incompatible with any single impactor or any known impact event.

GSA Today: v. 18, no. 1, doi: 10.1130/GSAT01801GW.1

*npinter@geo.siu.edu

${ }^{1}$ GSA Data Repository item 2008049, Figures DR1 (wind directions at Hither Hills State Park, Montauk, New York, USA, and Faux Cap, Madagascar) and DR2 (five photos of glassy and metallic microspherules and spherular carbon condensates), is available at www.geosociety.org/pubs/ft2008.htm. You can also obtain a copy by writing to editing@geosociety.org. 
In actuality, almost all of the material reported at $12.9 \mathrm{ka}$ is ubiquitous throughout the geological record. Glassy and metallic spherules are found in Antarctic ice (e.g., Taylor et al., 1998), in deep-sea sediments (e.g., Petterson and Fredriksson, 1958), and in peat bogs (e.g., Franzén, 2006). This material results from the steady rain of micrometeorites through the atmosphere, the majority ablating and settling to the surface as dust. Glassy spherules also derive from numerous anthropogenic processes and products. In addition, both anthropogenic combustion and natural wildfires produce both glassy and carbon spherular forms (Franzén, 2006) (Fig. DR2 [see text footnote one]).

The suggestion that some of the material identified as $12.9 \mathrm{ka}$ represents extraterrestrial input is consistent with its reported iridium content (Firestone et al., 2007a, 2007c), but we suggest that these levels simply represent the expected composition of micrometeorite ablation fallout. "[F]ullerenes enriched in ${ }^{3} \mathrm{He}$ " (Firestone et al., 2007c; Becker et al., 2007) are consistent with micrometeorite ablation fallout, although it must be noted that the fullerene and helium signals have been repeatedly characterized as nonreproducible (e.g., Taylor and Abdul-Sada, 2000; Farley and Mukhopadhyay, 2001; Buseck, 2002; Farley et al., 2005). Nanodiamonds may represent a true extraterrestrial signature, but this material was identified only obliquely and requires rigorous corroboration.

The 12.9-ka impact theory also runs roughshod over a wide range of other evidence. The claim that American megafauna disappeared precisely at $12.9 \mathrm{ka}$ is contrary to broad evidence that these extinctions were diachronous in space, across genera, and dependent on local geographical conditions (Fiedel, 2008). Similarly, the "black mat" horizons characterized by the Firestone group as a single hemisphere-wide impact-induced wildfire are elsewhere reported as multiple horizons of wetland deposits that span the latest Pleistocene-Holocene (Quade et al., 1998). Furthermore, impact-generated wildfire from California to Europe is impossible because thermal radiation is zero below the horizon $\longrightarrow 1000 \mathrm{~km}$ even for a massive 100-km-high fireball-and ignition by "reentry of high-speed, superheated ejecta" (Firestone et al., 2007c) is inconsistent with an atmospheric airburst (i.e., no impact and no ejecta). By invoking impact ignition, Firestone et al. ignore extensive literature documenting widespread burning at the vanguard of human migration into the Americas (e.g., Moreno, 2000; Pinter and Anderson, 2006).

Both the 12.9-ka impact and the Holocene mega-tsunami appear to be spectacular explanations on long fishing expeditions for shreds of support. Both stories have played out primarily in the popular press, highlighting how successful impact events can be in attracting attention. The desire for such attention is understandable in an environment where science and scientific funding are increasingly competitive. The National Science Foundation now emphasizes "transformative" research, and few events are as transformative as an impact. In an era when evolution, geologic deep time, and global warming are under assault, this type of "science by press release" and spectacular stories to explain unspectacular evidence consume the finite commodity of scientific credibility.

\section{REFERENCES CITED}

Abbott, D., Bryant, T., Gusiakov, V., and Masse, W., 2007, Megatsunami of the world ocean: Did they occur in the recent past?: Eos (Transactions, American Geophysical Union), v. 88, no. 23, Joint Assembly Supplement, Abstract PP42A-04.
Becker, L., Poreda, R., Kennett, J., West, A., and Wolbach, W., 2007, The end Pleistocene extinction event-what caused it?: Eos (Transactions, American Geophysical Union), v. 88, no. 23, Joint Assembly Supplement, Abstract PP41A-03.

Blakeslee, S., 2006, Ancient crash, epic wave: The New York Times, 14 Oct. 2006 , Section F, p. 1.

Bland, P.A., and Artemieva, N.A., 2006, The rate of small impacts on Earth: Meteoritics \& Planetary Science, v. 41, p. 607-631.

Bland, P.A., de Souza Filho, C.R., Jull, A.J.T., Kelley, S.P., Hough, R.M., Artemieva, N.A., Pierazzo, E., Coniglio, J., Pinotti, L., Evers, V., and Kearsley, A.T., 2002, A possible tektite strewn field in the Argentinian Pampa: Science, v. 296, p. 1109-1111, doi: $10.1126 /$ science. 1068345

Buseck, P.R., 2002, Geological fullerenes; review and analysis: Earth and Planetary Science Letters, v. 203, p. 781-792, doi: 10.1016/S0012-821X(02)00819-1.

Chapman, C.R., and Morrison, D., 1994, Impacts on Earth by asteroids and comets: Assessing the hazard: Nature, v. 367, p. 33-39, doi: 10.1038/367033a0.

Farley, K.A., and Mukhopadhyay, S., 2001, An extraterrestrial impact at the Permian-Triassic boundary?: Science, v. 293, p. 2211, doi: 10.1126/science.1065352.

Farley, K.A., Ward, P., Garrison, G., and Mukhopadhyay, S., 2005, Absence of extraterrestrial ${ }^{3} \mathrm{He}$ in Permian-Triassic age sedimentary rocks: Earth and Planetary Science Letters, v. 240, p. 265-275, doi: 10.1016/..epsl.2005.09.054.

Fiedel, S., 2008, Sudden deaths: The chronology of terminal Pleistocene megafaunal extinction, in Haynes, G., American megafaunal extinctions at the end of the Pleistocene: Berlin, Springer, in press.

Firestone, R.B., and Topping, W., 2001, Terrestrial evidence of a nuclear catastrophe in Paleoindian times: Mammoth Trumpet, v. 16, no. 2, p. 9-16.

Firestone, R., West, A., and Warwick-Smith, S., 2006, The Cycle of Cosmic Catastrophes: Flood, Fire, and Famine in the History of Civilization: Rochester, Vermont, Bear \& Company, $392 \mathrm{p}$.

Firestone, R.B., West, A., Revay, Z., Belgya, T., Smith, A., and Que Hee, S., 2007a, Evidence for a massive extraterrestrial airburst over North America 12.9 ka ago: Eos (Transactions, American Geophysical Union), v. 88, no. 23, Joint Assembly Supplement, Abstract PP41A-01.

Firestone, R.B., West, A., Revay, Z., Belgya, T., Smith, A., and Que Hee, S., 2007b, Evidence for an extraterrestrial impact event 12,900 years ago that contributed to megafaunal extinctions and the Younger Dryas cooling: Eos (Transactions, American Geophysical Union), v. 88, no. 23, Joint Assembly Supplement, Abstract PP43A-01.

Firestone, R.B., West, A., Revay, Z., Belgya, T., Smith, A., and Que Hee, S., 2007c, Evidence for an extraterrestrial impact 12,900 years ago that contributed to the megafaunal extinctions and the Younger Dryas cooling: Proceedings of the National Academy of Sciences of the United States of America, v. 104, p. 16,016-16,021, doi: 10.1073/ pnas.0706977104.

Franzén, L.G., 2006, Mineral matter, major elements, and trace elements in raised bog peat: A case study from southern Sweden, Ireland and Tierra del Fuego, south Argentina, in Martini, I.P., Cortizas, A.M., and Chesworth, W., eds., Peatlands: Evolution and Records of Environmental and Climate Changes: Amsterdam, Elsevier, p. 241-269.

Grant, J.A., Brooks, M.J., and Taylor, B.E., 1998, New constraints on the evolution of Carolina Bays from ground-penetrating radar: Geomorphology, v. 22, p. 325-345, doi: 10.1016/S0169-555X(97)00074-3.

Gusiakov, S., 2006, International Tsunami Expedition in Southern Madagascar, August 29September 13, 2006: Tsunami Laboratory, Institute of Computational Mathematics and Mathematical Geophysics, Siberian Division Russian Academy of Sciences, http://tsun.sscc.ru/Madagascar2006.htm (accessed 4 Oct. 2007).

Ivester, A.H., Brooks, M.J., and Taylor, B.E., 2007, Sedimentology and ages of Carolina Bay sand rims: Geological Society of America Abstracts with Programs, v. 39, no. 2 , p. 5.

LeBigre, J.-M., and Reaud-Thomas, G., 2001. Androka Extreme-sud de Madagascar: Cartes d'Evolution des Mileux: Bordeaux, Presses Universitaires de Bordeaux, $69 \mathrm{p}$.

Masse, W., Bryant, E., Gusiakov, V., Abbott, D., Rambolamana, G., Raza, H., Courty, M., Breger, D., Gerard-Little, P., and Burckle, L., 2006, Holocene Indian Ocean cosmic impacts: The megatsunami chevron evidence from Madagascar: Eos (Transactions, American Geophysical Union), v. 87, no. 52, Fall Meeting Supplement, Abstract PP43B-1244.

Moreno, P.I., 2000, Climate, fire, and vegetation between about 13,000 and 9200 ${ }^{14} \mathrm{C}$ yr B.P. in the Chilean Lake District: Quaternary Research, v. 54, p. 81-89, doi: $10.1006 /$ qres.2000.2148.

Petterson, H., and Fredriksson, K., 1958, Magnetic spherules in deep-sea deposits: Pacific Science, v. 12, p. 71-81.

Pierazzo, E., and Melosh, H.J., 2000, Understanding oblique impacts from experiments, observations, and modeling: Annual Review of Earth and Planetary Sciences, v. 28, p. 141-167, doi: 10.11 46/annurev.earth.28.1.141.

Pinter, N., and Anderson, S.A., 2006, A mega-fire hypothesis for latest Pleistocene paleo-environmental change on the Northern Channel Islands, California: Geological Society of America Abstracts with Programs, v. 38, no. 7, p. 66-13.

Quade, J., Forester, R.M., and Pratt, W.L., 1998, Black mats, spring-fed streams, and late-glacial-age recharge in the southern Great Basin: Quaternary Research, v. 49, p. 129-148, doi: 10.1006/qres.1997.1959.

Speranza, F., Sagnotti, L., and Rochette, P., 2004, An anthropogenic origin of the "Sirente crater," Abruzzi, Italy: Meteorics \& Planetary Science, v. 39, p. 635-649.

Taylor, R., and Abdul-Sada, A.K., 2000, There are no fullerenes in the K-T boundary layer: Fullerene Science and Technology, v. 8, p. 47-54.

Taylor, S., Lever, J.H., and Harvey, R.P., 1998, Accretion rate of cosmic spherules measured at the South Pole: Nature, v. 392, p. 899-903, doi: 10.1038/31894. 